\title{
Population structure and colony composition of two Zootermopsis nevadensis subspecies
}

\author{
BT Aldrich ${ }^{1}$ and S Kambhampati \\ Department of Entomology, Kansas State University, Manhattan, KS, USA
}

\begin{abstract}
Understanding the origin and maintenance of eusociality in termites has proved problematic, in part, due to a lack of knowledge concerning the variability and evolutionary changes in termite breeding structure. One way to address this is to compare the population genetics of a broad range of termite species. However, few studies have investigated the population genetics of basal termite taxa. We used 12 polymorphic microsatellite loci to characterize and compare the colony genetic structure of 18 colonies of two basal termite subspecies, Zootermopsis nevadensis nevadensis and Zootermopsis nevadensis nuttingi. The average relatedness $(r)$ among individuals within a colony was high (0.59) and similar to values reported for other termite species. Average relatedness between colony founders was lower (0.21) suggesting the alates outbreed. Genotypes of workers and soldiers in 4 out of the 18 colonies were consistent with
\end{abstract}

reproduction by a single pair of primary reproductives and the remaining colonies were inferred to have been derived from more than two reproductives. Eleven colonies with three or more reproductives were consistent with replacement reproductives (neotenics) and the remaining three colonies included genetic contribution from three or more primary reproductives. Comparisons between the subspecies revealed significant differences in breeding structure, specifically in the number and types of reproductives (that is, primaries or neotenics). Furthermore, we observed a larger proportion of colonies with greater than three primary reproductives compared to more derived termite lineages. Thus, our results suggest that breeding structure can vary significantly among termite taxa.

Heredity (2007) 99, 443-451; doi:10.1038/sj.hdy.6801022; published online 4 July 2007

Keywords: Zootermopsis; microsatellites; relatedness; termites; colony composition

\section{Introduction}

Comparative studies on the colony genetic structure of solitary, primitively eusocial and eusocial taxa have provided important insights into the diverse social structure and evolution of eusociality in Hymenoptera (Crozier and Pamilo, 1996; Pamilo et al., 1997; Ross, 2001; Wilson and Hölldobler, 2005). Similarly, understanding eusociality in Isoptera may depend on empirical evidence from genetic studies and a better understanding of the diversity and evolutionary changes in termite breeding structure. To this end, there is a growing number of population genetic studies involving termites (Reilly, 1987; Atkinson and Adams, 1997; Thompson and Hebert, 1998; Husseneder et al., 1999, 2002; Jenkins et al., 1999; Bulmer et al., 2001; Goodisman and Crozier, 2002; Vargo, 2003; Vargo et al., 2003, 2006a, b; DeHeer and Vargo, 2004; DeHeer et al., 2005; Dronnet et al., 2005; Hacker et al., 2005; Husseneder et al., 2005; Vargo and Carlson, 2006). The results of such studies have greatly increased our understanding of termite colony structure. Unfortunately, a majority of the termite population genetics studies involve only a few families and, with

Correspondence: Dr S Kambhampati, Department of Entomology, Kansas State University, Manhattan, KS 66506, USA.

E-mail: srini@ksu.edu

${ }^{1}$ Current address: Department of Anesthesia, University of Iowa, Iowa City, IA 52242, USA.

Received 6 February 2007; revised 15 May 2007; accepted 28 May 2007; published online 4 July 2007 the exception of Mastotermes darwiniensis, highly derived termite lineages. Consequently, population genetic studies of additional, basal taxa are needed to facilitate a broader comparison and greater understanding of variability in colony structure among diverse termite lineages. Studies of this nature have the potential to reveal evolutionary changes in termite colony structure and social characteristics and possibly, common patterns from which general rules underlying termite breeding structure could be derived (Ross, 2001).

According to phylogenetic evidence (Kambhampati and Eggleton, 2000), next to Mastotermitidae, Termopsidae is one of the basal termite families whose members are yet to be studied from a colony genetic structure standpoint. Termopsidae display one-piece nesting (living in and consuming their host log) and lack 'true' workers (nonreproductive, nonsoldier individuals that diverge early and irreversibly from the imaginal line) (Thorne, 1997; Thorne and Traniello, 2003), character states that are not present in the termite taxa whose population genetics have been studied to date. Among termopsids, the best-studied termites are in the genus Zootermopsis (see Krishna and Weesner, 1969; Thorne et al., 1993; Abe et al., 2000 for reviews), which are the only endemic termites in Nearctic temperate forests of western North America (Eggleton 2000). Because of their basal position and unique characteristics, studies on the population genetics of Zootermopsis should provide valuable information concerning termite colony structure diversity. 
The genus Zootermopsis consists of Zootermopsis nevadensis, Zootermopsis angusticollis and Zootermopsis laticeps (Banks). Z. nevadensis is subdivided into two subspecies, Zootermopsis nevadensis nevadensis and Zootermopsis nevadensis nuttingi (Haverty and Thorne, 1989). Comparative studies have shown that breeding structure can vary among sympatric populations of different species within the same termite family (Vargo et al., 2006b). Therefore, to characterize the differences in colony structure among the basal and derived termite lineages, it is important to understand the variability in colony structure among closely related taxa. This information may prove vital in differentiating between the intra- and intertaxon variability in colony structure and allow for more meaningful comparisons among termites lineages. Because they are the most closely related of the Zootermopsis taxa, a comparison of the population genetics of Z.n. nevadensis and Z.n. nuttingi should provide important information concerning the variability in colony structure within the genus.

Finally, the two Z. nevadensis subspecies are morphologically indistinguishable but display subspecies-specific cuticular hydrocarbon profiles (Haverty et al., 1988; Haverty and Thorne, 1989). No diagnostic genetic differences have been reported for the two Z. nevadensis subspecies.

Therefore, our objectives were to (1) identify diagnostic genetic differences between the $Z$. nevadensis subspecies, (2) characterize and compare the breeding and colony genetic structure of the two $Z$. nevadensis subspecies and (3) compare the breeding structure of $Z$. nevadensis subspecies to other termite species.

\section{Materials and methods}

\section{Sampling and identification}

Samples of Z. n. nevadensis and Z. n. nuttingi were collected from tree stumps and fallen logs at 18 sites in northern California during July 2003 (Table 1). The sampling locations for the two subspecies were chosen based on distribution data of Thorne et al. (1993). Sites 1-9 were located northwest of McCloud, CA and sites 10-18 southeast of Hat Creek, CA, which correspond to the known distribution of $Z$. n. nuttingi and $Z$. $n$. nevadensis, respectively, based on cuticular hydrocarbon phenotypes (Thorne et al., 1993). Fifty to one hundred workers and soldiers were collected from a single colony at each site. Specimens collected and stored in 95\% ethanol were returned to the Department of Entomology, Kansas State University, for genetic analysis. Live specimens from eight sites (indicated in Table 1) were sent to Michael Haverty (USDA Forest Service, Berkeley, CA, USA) for hydrocarbon analysis (Haverty et al., 1988).

\section{Mitochondrial DNA}

To determine if the two subspecies displayed genetic variability at a maternally inherited marker, we used polymerase chain reaction (PCR) to amplify a portion of the cytochrome oxidase subunit I (COI) mitochondrial gene fragment, which has been used as a species-specific marker (Brunner et al., 2002; Hebert et al., 2003; Stoeckle, 2003). DNA was extracted from the head and thorax of a single individual chosen at random from each of the 18 colonies using the Wizard DNA isolation kit (Promega Corp., Madison, WI, USA). The COI fragment was amplified from each of the selected individuals using the primers: COIF: $5^{\prime}$-GAA CAG AAC TTG GAC AAC A-3' and COIR: 5'-CTA CTG TGA ATA TGT GGT GTG C-3'. The primers were designed from COI sequences of other termite species (Aanen et al., 2002; Aanen and Eggleton, 2005). PCR was set up in $31 \mu$ l volumes containing $22.5 \mu \mathrm{l} \mathrm{H}_{2} \mathrm{O}, 2.5 \mu \mathrm{l}$ of $10 \times$ Taq buffer $(500 \mathrm{mM} \mathrm{KCl}, 100 \mathrm{mM}$ Tris- $\mathrm{HCl}$ (pH 9.2), $1 \%$ Triton X-100), $2.5 \mu \mathrm{l} \mathrm{MgCl}_{2}$ (25 mM), $0.25 \mu \mathrm{l}$ dNTPs ( $\left.80 \mathrm{mM}\right)$ (Promega), $0.4 \mu \mathrm{l}$ of each primer $(0.25 \mu \mathrm{g} / \mu \mathrm{l}), 0.4 \mu \mathrm{l}$ of Taq DNA polymerase (Promega) and $2 \mu \mathrm{l}$ of DNA. Amplification was achieved using a PTC-200 Thermal

Table 1 Sampling data for Z. nevadensis subspecies in California

\begin{tabular}{|c|c|c|c|c|c|c|}
\hline Site no. & Location & Latitude (N) & Longitude (W) & Altitude (m) & Subspecies & COI haplotype \\
\hline $1^{*}$ & Klamath National Forest & 41.51 .29 & 122.42 .14 & 1878 & Z.n. nuttingi & I \\
\hline $2^{*}$ & Klamath National Forest & 41.51 .26 & 122.42 .08 & 1976 & Z.n. nuttingi & I \\
\hline 3 & Klamath National Forest & 41.50 .50 & 122.41 .01 & 2070 & Z.n. nuttingi & I \\
\hline $4^{*}$ & Edgewood+Calhan & 41.25 .85 & 122.38 .33 & 4770 & Z.n. nuttingi & I \\
\hline $5^{*}$ & Edgewood+Calhan & 41.24 .73 & 122.37 .94 & 4509 & Z.n. nuttingi & I \\
\hline $6^{*}$ & Hwy 3 south of Scott mts. trail & 41.15 .56 & 122.40 .20 & 4875 & Z.n. nuttingi & I \\
\hline $7^{*}$ & Hwy 3 south of Scott mts. trail & 41.14 .79 & 122.39 .89 & 4874 & Z.n. nuttingi & I \\
\hline 8 & Dunsmuir & 41.09 .75 & 122.17 .28 & 1944 & Z.n. nuttingi & I \\
\hline 9 & Dunsmuir & 41.10 .32 & 122.15 .78 & 1944 & Z.n. nuttingi & I \\
\hline $10^{*}$ & 2 miles south of Hat Creek & 40.47.19 & 121.30 .29 & 4038 & Z. n. nevadensis & II \\
\hline $11^{*}$ & 10 miles south of Hat Creek & 40.44 .54 & 121.28 .33 & 3590 & Z. n. nevadensis & II \\
\hline 12 & 3 miles south of Old Station & 40.41 .73 & 121.23 .28 & 5170 & Z. n. nevadensis & II \\
\hline 13 & 6 miles south of Old Station & 40.40 .00 & 121.21 .51 & 5620 & Z. n. nevadensis & II \\
\hline 14 & 10 miles south of Old Station & 40.38 .76 & 121.18.15 & 5455 & Z. n. nevadensis & II \\
\hline 15 & Milford & 40.07.77 & 120.20 .80 & 5593 & Z. n. nevadensis & II \\
\hline 16 & Milford & 40.07.77 & 120.20 .80 & 5593 & Z. n. nevadensis & II \\
\hline 17 & Milford & 40.07 .62 & 120.20 .74 & 5631 & Z. n. nevadensis & II \\
\hline 18 & Milford & 40.07.19 & 120.20 .86 & 6041 & Z. n. nevadensis & II \\
\hline $19^{*}$ & Pebble Beach & 36.36 .05 & 121.52 .54 & 60 & Z.n. nuttingi & I \\
\hline $20^{*}$ & Georgetown & 38.54 .25 & 120.50 .15 & 2649 & Z. n. nevadensis & II \\
\hline
\end{tabular}

Abbreviations: COI, cytochrome oxidase subunit I; Hwy, highway; mts, mountains.

Sites with asterisk indicate colonies identified via cuticular hydrocarbons. COI haplotype indicates the haplotype I or II displayed by the individual sampled and sequenced from each colony. 
Cycler (MJ Research, Waltham, MA, USA) with the following conditions: an initial denaturation step of $94^{\circ} \mathrm{C}$ ( $3 \mathrm{~min}$ ) followed by 10 cycles of $95^{\circ} \mathrm{C}(30 \mathrm{~s}), 45^{\circ} \mathrm{C}(45 \mathrm{~s})$ and $72^{\circ} \mathrm{C}(30 \mathrm{~s})$, then 25 cycles of $95^{\circ} \mathrm{C}(30 \mathrm{~s}), 50^{\circ} \mathrm{C}(45 \mathrm{~s})$ and $72^{\circ} \mathrm{C}(30 \mathrm{~s})$ followed by $72^{\circ} \mathrm{C}$ for $20 \mathrm{~min}$. The PCR fragments were gel purified and sequencing reactions using the dRhodamine Dye Terminator Kit (ABI Inc., Foster City, CA, USA) were set up following the manufacturer's instructions. The DNA pellet was dried and sent to the University of Florida's DNA sequencing laboratory for sequencing on an ABI 377 sequencer. The COI gene fragment of two additional individual termites from Pebble Beach and Georgetown, CA (previously identified as $Z$. n. nuttingi and $Z$. n. nevadensis, respectively, based on cuticular hydrocarbons by Haverty) were sequenced to determine if subspecies-specific sequence variability was maintained over a broader geographic range. The Pebble Beach and Georgetown, CA samples were collected $\sim 500$ and $\sim 150 \mathrm{~km}$ from our Z. n. nuttingi and Z. n. nevadensis colonies, respectively. Sequences are deposited in Genbank under accession numbers DQ133197-DQ133206 (Z. n. nuttingi) and DQ133207-DQ133216 (Z.n. nevadensis).

\section{Microsatellite analysis}

DNA was extracted from the head and thorax of 26-54 individuals from each colony. Twelve polymorphic microsatellite loci were amplified for each individual using primers and methods reported by Aldrich and Kambhampati (2004). PCR products were run on $6 \%$ polyacrylamide gels on a Hoeffer SE 600 gel system (GE Healthcare, Piscataway, NJ, USA), stained with ethidium bromide and visualized and photographed under UV light. Alleles were scored based on fragment size. Running samples with molecular weight markers and PCR products containing allele fragments from previous samples ensured accurate identification and scoring of alleles.

Hardy-Weinberg equilibrium and linkage disequilibrium Because of the close genetic relationship among colony members, genotypes of individuals within a colony are not independent. Therefore, a single individual from each colony was selected at random and deviations from Hardy-Weinberg equilibrium (HWE) and linkage disequilibrium (LD) were analyzed by means of exact tests using GENETIC DATA ANALYSIS v. 1.1 (Lewis and Zaykin, 2000) with 3200 iterations as described by Vargo (2003). The two sub-species were analyzed separately and the procedure was replicated 20 times for each subspecies.

\section{Colony structure}

The reproductives in Zootermopsis colonies can be of one of two types: primaries, which are alate-derived reproductives, or neotenics, which are workers or soldiers that have differentiated into functional reproductives. To assess the family structure (that is, type and number of reproductives within each colony), genotypes and allele frequencies within colonies were used to classify colonies as simple family, extended family or mixed family colonies as defined by DeHeer and Vargo (2004). Simple family colonies were those in which four or fewer genotypic classes were observed and observed frequen- cies of genotypes did not differ significantly from expected Mendelian frequencies as determined by a G-test (Vargo, 2003). Individuals in simple family colonies exhibit genotypes that are consistent with being derived from a single pair of reproductives. Extended family colonies were those in which five or more genotypic classes were observed or those in which genotype frequencies deviated significantly from expected Mendelian ratios $(P<0.05, G$-test). Mixed family colonies were those in which five or more alleles were observed at a single locus. Individuals in extended and mixed family colonies exhibit genotypes that suggest three or more reproductives are responsible for progeny production. The distinction between extended and mixed family colonies is in the number of primary reproductives. Extended family colonies contain neotenics and offspring that are descendents of a single founding pair of primary reproductives. Mixed family colonies contain offspring of three or more primary reproductives but may also include those of some neotenics.

\section{Subspecies comparisons and population genetic structure}

To quantify and compare the breeding structure of $Z$. nevadensis subspecies, we analyzed colonies 1-9 and 10-18 separately because each set of colonies exhibited fixed genetic differences in mitochondrial COI gene (see 'Results') that correspond to the geographic distribution of the two subspecies (Thorne et al., 1993). Unless specified, all analyses were carried out using MSANALYZER 3.15 (Dieringer and Schlotterer, 2003). Genetic variability was assessed by estimating the number of alleles at each locus, observed heterozygosity and expected heterozygosity (Nei, 1973) for all loci. To quantify the higher-level breeding structure, direct estimates of the proportion of the total genetic variability at three hierarchical levels, namely, among locations, among colonies and within colonies, were obtained using the analysis of molecular variance (AMOVA) in ARLEQUIN 2.0 (Schneider et al., 2000). ARLEQUIN was also used to assess the proportion of the total variation for all samples that is due to variability among the subspecies. F-statistics were used to estimate population substructuring within the two subspecies at three hierarchical levels: among all individuals $\left(F_{\mathrm{IT}}\right)$, among colonies $\left(F_{\mathrm{CT}}\right)$ and within colonies $\left(F_{\mathrm{IC}}\right)$. Within each subspecies, $F$-statistic estimates were calculated separately for each colony type (simple, extended and mixed) and were then compared to different models of termite breeding structure (Thorne et al., 1999; Bulmer et al., 2001; DeHeer et al., 2005). T-tests were used to determine if observed heterozygosity and F-statistic estimates were significantly different among loci within a subspecies and between colony types, respectively.

\section{Relatedness within and among colonies and parents}

The coefficient of relatedness among workers and reproductives from the same and different colonies was estimated using the program RELATEDNESS 5.0.8 (Queller and Goodnight, 1989). To determine how the number and type of reproductives (that is, primaries and neotenics) impacted relatedness among colonymates, relatedness among individuals within each colony was estimated. Colonies were grouped based on the classifi- 
cations mentioned above and $t$-tests were used to estimate if relatedness estimates were significantly different among the three different colony types. To estimate whether population substructuring influenced the relatedness among colonies, we estimated the coefficient of relatedness between all pairwise combinations of colonies. We then compared the relatedness among colonies within a location to that among colonies from different locations. To estimate the relationship between primary colony founders we reconstructed, both manually and using the computer program GERUD 2.0 (Jones, 2005), the parental genotypes for each simple family colony using the genotypes of the offspring. Using the reconstructed parental genotypes, we estimated the relatedness between parents of each simple family colony. All reported relatedness estimates are relative to the entire population (that is, relatedness above the baseline relatedness among individuals of a population).

\section{Results}

\section{Mitochondrial DNA haplotypes}

Cuticular hydrocarbon phenotyping of the eight colonies identified two different hydrocarbon profiles corresponding to Z.n. nevadensis and Z. n. nuttingi as reported previously by Haverty et al. (1988). In agreement with the distributional data (Thorne et al., 1993), all Z. n. nuttingi colonies were located northwest of McCloud, CA, and all Z. n. nevadensis colonies southeast of Hat Creek, CA (Figure 1 and Table 1). The DNA sequence of the $772 \mathrm{bp}$ COI gene fragment from one individual from each of the 18 colonies revealed the presence of two unique haplotypes. The first haplotype displayed thymine at position 127 and adenine at position 699 (haplotype I) whereas the second haplotype displayed a cytosine and guanine at the above two respective positions (haplotype II). Additionally, haplotype I was found in colonies located northwest of McCloud, CA (that is, Z.n.nuttingi) whereas haplotype II was found in colonies southeast of Hat Creek, CA (that is, Z. n. nevadensis) (Table 1). Furthermore, two individuals sampled from Pebble Beach and Georgetown, CA (identified as Z. n. nuttingi and Z. n. nevadensis, respectively, using hydrocarbon analysis) displayed haplotypes I and II, respectively. Thus, the COI sequence provides a genetic distinction between Z. n. nuttingi and Z. n. nevadensis as defined by hydrocarbon phenotypes.

\section{Basic microsatellite data}

In total, 86 different alleles were observed at the 12 loci ranging from 4 to 11 alleles per locus and an average of 7 alleles per locus (Table 2). The Z. n. nuttingi colonies contained 67 alleles including 6 private alleles and Z. $n$. nevadensis colonies contained 80 alleles including 19 private alleles. For both subspecies, the observed heterozygosities were significantly larger than those expected under HWE $\left(t_{11}=7.35, P<0.01\right.$ for $Z$. n. nuttingi and

Table 2 Number of alleles observed at each locus for Z. nevadensis sampled in this study

\begin{tabular}{lccr}
\hline Locus & Common alleles & Private alleles & Total \\
\hline Zoot11 & 3 & 2 & 5 \\
Zoot18 & 3 & 5 & 8 \\
Zoot25 & 6 & 1 & 7 \\
Zoot28 & 8 & 3 & 11 \\
Zoot29 & 4 & 1 & 5 \\
Zoot31 & 2 & 6 \\
Zoot73 & 8 & 2 & 10 \\
Zoot76 & 5 & 4 & 9 \\
Zoot101 & 5 & 1 & 6 \\
Zoot103 & 3 & 1 & 4 \\
Zoot117 & 10 & 0 & 10 \\
Zoot212 & 2 & 3 & 5
\end{tabular}

Common alleles were observed in both subspecies and private alleles were those found in only one of the two subspecies.

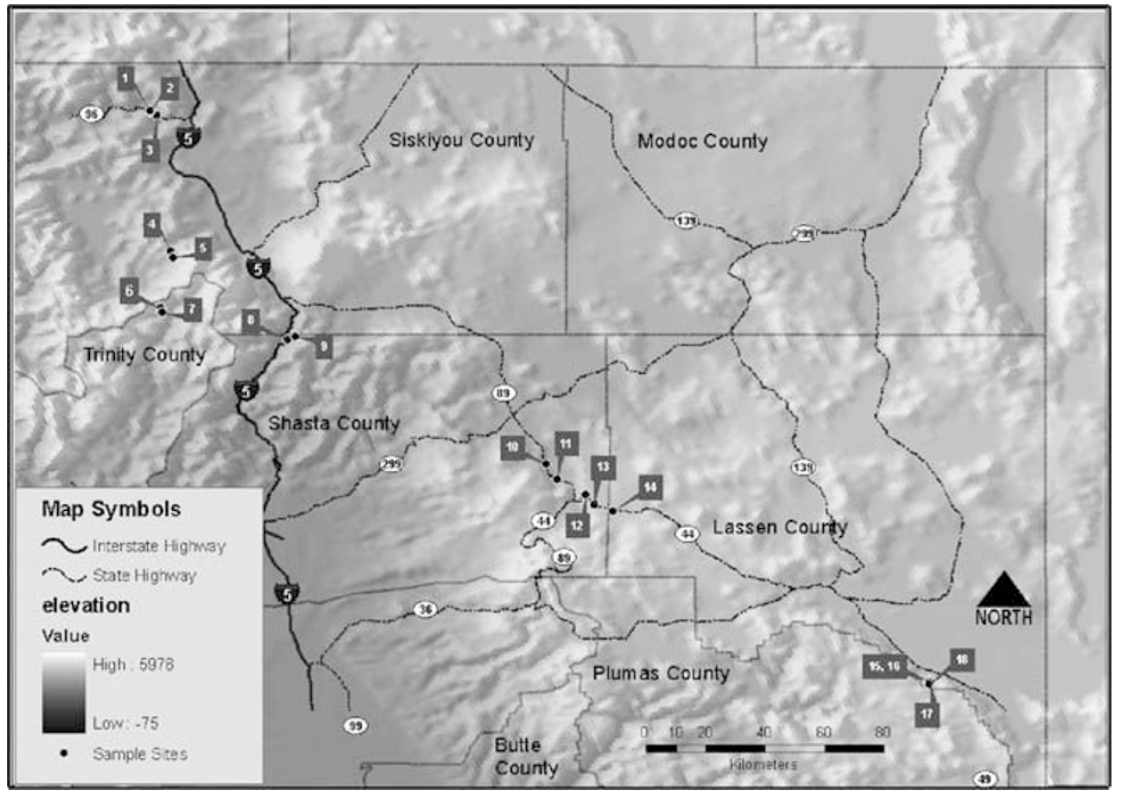

Figure 1 Map showing the distribution of Z.n.nuttingi and Z.n. nevadensis colonies included in this study (Z.n.nuttingi, 1-9; Z.n.nevadensis, 10-18). 
Table 3 Locus-specific and mean observed and expected heterozygosity estimates for Z. n. nuttingi and Z. n. nevadensis colonies

\begin{tabular}{|c|c|c|c|c|}
\hline \multirow[t]{2}{*}{ Locus } & \multicolumn{2}{|c|}{ Z. n. nuttingi } & \multicolumn{2}{|c|}{ Z. n. nevadensis } \\
\hline & Het obs & Het exp & Het obs & Het exp \\
\hline Zoot29 & 0.40 & 0.33 & 0.53 & 0.42 \\
\hline Zoot18 & 0.30 & 0.25 & 0.49 & 0.37 \\
\hline Zoot25 & 0.56 & 0.43 & 0.70 & 0.56 \\
\hline Zoot212 & 0.21 & 0.19 & 0.45 & 0.33 \\
\hline Zoot117 & 0.59 & 0.52 & 0.67 & 0.59 \\
\hline Zoot11 & 0.41 & 0.32 & 0.44 & 0.34 \\
\hline Zoot73 & 0.69 & 0.58 & 0.76 & 0.62 \\
\hline Zoot76 & 0.63 & 0.45 & 0.61 & 0.46 \\
\hline Zoot101 & 0.70 & 0.59 & 0.65 & 0.52 \\
\hline Zoot103 & 0.54 & 0.45 & 0.43 & 0.38 \\
\hline Zoot28 & 0.55 & 0.50 & 0.65 & 0.48 \\
\hline Zoot31 & 0.64 & 0.53 & 0.52 & 0.44 \\
\hline Mean & 0.52 & 0.43 & 0.57 & 0.46 \\
\hline s.e. & 0.02 & 0.01 & 0.02 & 0.01 \\
\hline
\end{tabular}

Abbreviations: Het obs, observed heterozygosity; Het exp, expected heterozygosity.

$t_{11}=11.81, P<0.01$ for $Z$. n. nevadensis; Table 3 ). The expected heterozygosities were not significantly different between the two subspecies $\left(t_{11}=1.31, P=0.22\right)$. Observed heterozygosities, ranged from 0.52 to 0.57 for the two subspecies but not significantly different from each other $\left(t_{11}=1.72, P=0.11\right)$. Locus-specific heterozygosity values varied but were not significantly different among loci or between the subspecies ( $t$-test, $P>0.05$ ).

\section{HWE and linkage disequilibrium}

The 12 loci used in this study showed significant deviation from HWE in 55 of the 240 (23\%) tests for Z. n. nuttingi and 20 of the $240(8 \%)$ tests for Z. $n$. nevadensis (20 replicates $\times 12$ loci). Significant LD was observed in 119 of 1320 (9\%) locus combinations for Z. $n$. nuttingi and 56 of the 1320 (4\%) locus combinations for Z. n. nevadensis (20 replicates $\times 66$ locus combinations). No one locus or pairs of loci showed consistent deviation from HWE or LD in the above tests. Therefore, all 12 loci were included in the following analyses.

\section{Classification of colonies according to breeding types}

Four of the eighteen colonies included in this study were consistent with being derived from a single pair of reproductives. Eleven colonies displayed five or more genotypic classes or genotype frequencies that deviated significantly from those expected under HWE (G-test, $P<0.05$ ), and were therefore considered extended family colonies. The remaining three colonies displayed five or more alleles at a single locus and were considered mixed family colonies. Of the nine Z. n. nevadensis colonies, four were simple family colonies, two were extended family colonies and three were mixed family colonies. All nine $Z$. n. nuttingi colonies sampled were inferred to be extended family colonies.

\section{Breeding structure}

Genetic variance was partitioned into variance among locations, among colonies and within colonies for $Z$. $n$. nuttingi and Z. n. nevadensis (Table 4). In general, variance estimates at each hierarchical level were similar between
Table 4 The total genetic variance in allele frequencies of $Z$. $n$. nuttingi and $Z$. n. nevadensis partitioned into variance among locations, among colonies and within colonies

\begin{tabular}{lcccccc}
\hline Source & \multicolumn{2}{c}{ Z. n. nuttingi } & & \multicolumn{2}{c}{ Z. n. nevadensis } \\
\cline { 2 - 3 } \cline { 5 - 6 } & $\begin{array}{c}\text { Variance } \\
\text { component }\end{array}$ & $\begin{array}{c}\text { \% of } \\
\text { total }\end{array}$ & & $\begin{array}{c}\text { Variance } \\
\text { component }\end{array}$ & $\begin{array}{c}\text { \% of } \\
\text { total }\end{array}$ \\
\hline Among & 0.11 & 4 & & 0.24 & 6 \\
$\begin{array}{l}\text { locations } \\
\begin{array}{l}\text { Among } \\
\text { colonies }\end{array}\end{array}$ & 0.94 & 29 & & 0.94 & 24 \\
Within colonies & 2.19 & 67 & & 2.79 & 70 \\
Total & 3.24 & 100 & & 3.97 & 100 \\
\hline
\end{tabular}

the two subspecies. The largest component of genetic variability was attributable to variation within colonies with a mean of $68.5 \%$ for both subspecies. Among-colony variability averaged across the two subspecies was $26.5 \%$. The remaining $5 \%$ of the variability was attributable to variability among colonies from different sampling locations. When analyzed together, about $10 \%$ of the total genetic variability could be attributed to differences between Z. n. nuttingi and Z. n. nevadensis colonies.

Within each subspecies and colony type, locus-specific $F$-statistic estimates were variable but not significantly different among loci (data not shown). Overall, F-statistic estimates were somewhat variable among the three colony types and between the two subspecies of the same colony type (Table 5). The departure from random mating among colonies $\left(F_{\mathrm{CT}}\right)$ was not significantly different between the two subspecies or among the three colony types ( $t$-test; $P>0.05)$. $F_{\text {IT }}$ estimates were somewhat variable between colonies but the estimates were significantly different only between the Z. n. nuttingi and Z. n. nevadensis extended family colonies $\left(t_{22}=2.63\right.$, $P=0.02)$. The colony-level inbreeding coefficient $\left(F_{\mathrm{IC}}\right)$ for Z. n. nuttingi extended family colonies was significantly different from both simple and extended family colony $F_{\mathrm{IC}}$ estimates for $Z$. $n$. nevadensis $\left(t_{22}=2.78\right.$, $P=0.01 ; t_{22}=2.81, P=0.01$, respectively). Listed in Table 5 are $F$-statistics and relatedness estimates generated from computer simulations of several different termite breeding systems (Thorne et al., 1999; Bulmer et al., 2001; DeHeer et al., 2005). F-statistics and relatedness estimates for $Z$. $n$. nevadensis simple family colonies were consistent with simulated values for simple family colonies (Table 5) and differed significantly (based on $95 \%$ confidence interval (CI)) in at least one of the four parameters $\left(F_{\mathrm{IT}}, F_{\mathrm{CT}}, F_{\mathrm{IC}}\right.$ and $\left.r\right)$ from all other breeding systems. The mixed family colonies of $Z$. n. nevadensis were consistent with pleometrosis involving two queens and one king (Table 5) and differed from all other systems examined. The extended family colonies for both subspecies differed from all simulated breeding systems in one or more of the parameters.

\section{Relatedness}

The average $r$ among workers within Zootermopsis colonies $(r=0.59 \pm 0.03$ (s.e.) $)$ was significantly greater 
Table 5 Summary of F-statistics and relatedness estimates for Z. n. nuttingi and Z. n. nevadensis colonies

\begin{tabular}{|c|c|c|c|c|}
\hline & $\mathrm{F}_{I T}$ & $\mathrm{~F}_{C T}$ & $\mathrm{~F}_{I C}$ & $\mathrm{r}$ \\
\hline \multicolumn{5}{|l|}{ Z. n. nuttingi } \\
\hline Extended family colonies $(N=9)$ & $0.24(0.17-0.31)$ & $0.32(0.25-0.40)$ & $-0.12(-0.20$ to -0.05$)$ & $0.62(0.56-0.69)$ \\
\hline \multicolumn{5}{|l|}{ Z. n. nevadensis } \\
\hline Simple family colonies $(N=4)$ & $0.15(-0.01$ to 0.28$)$ & $0.33(0.24-0.42)$ & $-0.28(-0.38$ to -0.17$)$ & $0.60(0.44-0.77)$ \\
\hline Extended family colonies $(N=2)$ & $0.02(-0.18$ to 0.21$)$ & $0.26(0.13-0.39)$ & $-0.33(-0.52$ to -0.14$)$ & $0.59(0.53-0.64)$ \\
\hline Mixed family colonies $(N=3)$ & $0.11(-0.06$ to 0.29$)$ & $0.25(0.11-0.39)$ & $-0.18(-0.24$ to -0.12$)$ & $0.46(0.29-0.63)$ \\
\hline \multicolumn{5}{|l|}{ Simulated } \\
\hline Simple family colonies & 0.00 & 0.25 & -0.33 & 0.50 \\
\hline Replacements $(n=1, X=1)$ & 0.33 & 0.42 & -0.14 & 0.62 \\
\hline Replacements $(n=1, X=3)$ & 0.57 & 0.65 & -0.22 & 0.82 \\
\hline Replacements $(n=10, X=1)$ & 0.33 & 0.34 & -0.01 & 0.51 \\
\hline Mixing between related colonies $(n=1, X=3, P=90)$ & 0.66 & 0.64 & 0.04 & 0.77 \\
\hline Pleometrosis (colonies headed by two queens and one king) & 0.00 & 0.19 & -0.23 & 0.38 \\
\hline
\end{tabular}

$N$ is the number of colonies sampled for each colony type. The $95 \%$ confidence interval for each estimate is given in parentheses; $F_{\mathrm{IT}}$ is the reduction in heterozygosity of individuals in the total population; $F_{\mathrm{CT}}$ is the mean reduction in heterozygosity of colonies in the total population; $F_{\mathrm{IC}}$ is the mean reduction in heterozygosity of individuals in a colony; $r$ is the coefficient of relatedness estimate among individuals within a colony; $n$ is the number of replacement reproductive pairs; $X$ is the number of generations of inbreeding among replacement reproductives; $P$ is the proportion of mixing between colonies.

than $0.50\left(t_{17}=4.16, P<0.01\right)$ expected for full siblings. The average $r$ for simple family colonies, extended colonies and mixed colonies was $0.60 \pm 0.07,0.62 \pm 0.02$ and $0.46 \pm 0.08$, respectively (Table 5). Relatedness estimates for simple family colonies were not significantly different from extended or mixed family colonies and extended family colonies were significantly different from mixed family colonies $\left(t_{12}=2.63, P=0.02\right)$. The average $r$ between individuals from two different colonies was $0.01 \pm 0.01$. The $r$ between individuals from two different colonies in the same location and two colonies from different locations was $0.01 \pm 0.03$ and $0.02 \pm 0.01$, respectively. The average $r$ between parents of simple family colonies was $0.21 \pm 0.08$.

\section{Discussion}

Genetic differences between the subspecies

Zootermopsis $n$. nevadensis and Z. n. nuttingi can be distinguished from each other using hydrocarbon profiles (Haverty and Thorne, 1989). However, no morphological or genetic differences have been reported to date. We identified fixed differences in the mitochondrial COI gene that indicate that the two subspecies are genetically differentiated lineages.

\section{Higher-level breeding structure of $Z$. nevadensis}

Colonies sampled in this study were collected over a large geographic area and, if significant population substructuring were to exist, the pooling of these colonies may have resulted in an overestimation of the $F$-statistics and relatedness estimates. However, there was little pattern in genetic differentiation above the colony level with only $5 \%$ of the genetic variation among colonies collected at different locations. To determine whether the pooling of colonies collected over a large area had a significant impact on the breeding structure estimates, we performed a simple test using five colonies collected within a $\sim 200 \mathrm{~m}$ area, which were part of a larger study involving a hybrid zone between the two Z. nevadensis subspecies (colonies 14-18; Aldrich, 2005). All five colonies displayed the Z. n. nuttingi haplotype and were located within $27 \mathrm{~km}$ of the $Z$. $n$. nuttingi samples included in this study. We calculated $F$-statistics and relatedness estimates for these five colonies independently and pooled with Z. n. nuttingi colonies 1-9 used in this study. There was a slight reduction (0.02 and 0.03 decrease, respectively) in Fstatistics and relatedness estimates in the pooled relative to the independent datasets; however, the pooled and independent estimates were not significantly different from each another $(P>0.05)$.

Low levels of population subdivision above the colony level and low relatedness among colonies within a location suggest that there is significant gene flow among colonies at different locations. Aldrich (2005) estimated weak, but significant evidence for isolation by distance among Z. nevadensis colonies over a range of $500 \mathrm{~m}-$ $170 \mathrm{~km}$, which suggests that during nuptial flights $Z$. nevadensis alates are dispersing, pairing and settling large $(>500 \mathrm{~m})$ distances from their parental colonies. This is consistent with the observed dispersal distance for Z. angusticollis of $>350 \mathrm{~m}$ (Castle, 1934). Our estimates are also consistent with those for other termite species (Reticulitermes, Mastotermes) indicating population differentiation occurs over moderate to large distances $(500 \mathrm{~m}-$ $100 \mathrm{~km}$ ) (Reilly, 1987; Jenkins et al., 1999; Bulmer et al., 2001; Goodisman and Crozier, 2002; Vargo, 2003; Vargo et al., 2003).

Colony classification, relatedness and breeding structure The number of simple, extended and mixed family colonies varied between $Z$. n. nuttingi and $Z$. $n$. nevadensis. One possible explanation for these differences is variability in the ages of colonies that were sampled. In general, the proportion of extended and mixed family colonies relative to simple family colonies is expected to increase with colony age (Thorne, 1998; Thorne et al., 1999, 2003). If the average ages of colonies differed between the two subspecies, differences in the 
number of simple, extended and mixed family colonies are expected. Differences in survivorship and behavior may also explain the observed differences in breeding structure. For example, neotenic development may occur more frequently in $Z$. n. nuttingi relative to $Z$. $n$. nevadensis. Alternatively, Z. n. nevadensis colonies may not be surviving long enough to develop into extended family colonies.

The Z. n. nevadensis simple family colonies display parental relatedness and colony $F_{\mathrm{IT}}$ estimates that are suggestive of the reproductives in these colonies being closely related (approaching half-sib values) and individuals in these colonies being significantly inbred, respectively. F-statistics and relatedness estimates were inconsistent with these colonies being derived from a single pair of replacement reproductives and instead suggest that these colonies were founded by related primary reproductives. However, the relatedness data suggest that alates are not pairing with siblings during colony formation. Instead, it is apparent that founding alates can share a significant portion of their genetic material in common with each other by random chance, resulting in inbred colonies. Several scenarios have been proposed to explain how alates avoid pairing with siblings, including synchronized swarming of alates (Weesner, 1960; Noirot and Bodot, 1964; Harris and Sands, 1965), long distance dispersal (Jones et al., 1981, 1988) and use of chemical or other cues to preferentially pair with nonsiblings (Shellman-Reeve, 2001).

Our finding that Z. n. nuttingi and Z. n. nevadensis extended family colonies were inconsistent with any one single simulated breeding system is not unique. Similar results have been reported in studies of other termite species and are likely to arise when colonies of a species consist of multiple breeding systems (DeHeer and Vargo, 2004; DeHeer et al., 2005). F-statistics and relatedness estimates for Z. n. nuttingi extended family colonies were most similar to those expected for a breeding system involving small numbers of replacement reproductives. Although classified as extended family colonies, breeding structure estimates for Z. n. nevadensis extended family colonies were most similar to values expected for simple family colonies. One possibility is that these colonies only recently developed neotenic reproductives and genetically were still most similar to simple family colonies. Alternatively, these colonies were a mix of more than one breeding system. Overall, our results suggest that the Z. nevadensis extended family colonies sampled in this study contain small numbers of replacement (neotenic) reproductives.

Mixed family colonies have been observed in several termite species (Broughton, 1995; Atkinson and Adams, 1997; Jenkins et al., 1999; Bulmer et al., 2001; Goodisman and Crozier, 2002; Hacker et al., 2005); however, relatively little is known about their development. $F_{\text {IC }}$ estimates for $Z$. n. nevadensis mixed family colonies were too low to be explained by accidental mixing of colonies, even related ones, at the collection sites. Instead, these colonies display breeding structure estimates consistent with pleometrosis. In pleometrosis multiple female alates cooperate during colony foundation and rapid colony expansion during the initial stages of colony growth ensues (Atkinson and Adams, 1997; Hacker et al., 2005). However, multiple factors other than pleometrosis have been proposed to explain mixed family colonies, includ- ing infiltration of mature colonies by other alates, sharing of foraging tunnels by neighboring colonies or colony fusion (DeHeer and Vargo, 2004). In Reticulitermes flavipes, mixed family colonies were the result of colony fusions (DeHeer and Vargo, 2004). However, Zootermopsis and Reticulitermes differ markedly in their life histories and corresponding differences in their breeding systems may exist.

\section{Comparisons among termites}

A key to understanding the evolution of termites is determining the variability in breeding and colony structure among different termite lineages. Overall, the $F$-statistics and relatedness estimates appear to vary among Mastotermitidae (Goodisman and Crozier, 2002), Rhinotermitidae (Vargo, 2003; Vargo et al., 2003; DeHeer and Vargo, 2004; DeHeer et al., 2005; Vargo et al., 2006b), Termitidae (Thompson and Hebert, 1998) and Termopsidae (this study). This interspecific variability arises from differences in relatedness between primary reproductives, number of neotenic reproductives and proportion of each colony type (Thorne et al., 1999; Bulmer et al., 2001). Studies of R. flavipes (Vargo, 2003), Schedorhinotermes lamanianus (Husseneder et al., 1999), Nasutitermes nigriceps (Thompson and Hebert, 1998), M. darwiniensis (Goodisman and Crozier, 2002) and Z.n. nuttingi (Shellman-Reeve, 2001, this study) have shown that termite colonies are typically founded by outbred reproductives. In contrast, high relatedness estimates $(r \geqslant 0.50)$ have been observed between primary reproductives in colonies of Coptotermes formosanus (Vargo et al., 2003).

Information concerning the number of neotenic reproductives in colonies of different termite species is limited; however, the frequency and number of neotenics appear to vary both within and among termite families. For example, C. formosanus (Vargo et al., 2003) shows a lower proportion of colonies with neotenics $(10 \%)$ compared to $M$. darwiniensis (47\%; Goodisman and Crozier, 2002), S. lamanianus (58\%; Husseneder et al., 1999) and Z. nevadensis (61\%; this study). With regard to the number of neotenics in extended family colonies, most colonies of Reticulitermes grassei consist of tens or hundreds of replacement reproductives (DeHeer et al., 2005), whereas $R$. flavipes (DeHeer and Vargo, 2004) and Z. nevadensis colonies typically consist of fewer than 10 neotenics.

The number of mixed family colonies varies within and among different termite families. Mastotermitidae (Goodisman and Crozier, 2002) and Termopsidae (this study) show the highest proportion of colonies derived from more than two primary reproductives (26 and $17 \%$, respectively). In Termitidae, mixed family colonies have been observed in studies of Nasutitermes corniger (Atkinson and Adams, 1997) and Macrotermes michaelseni (Hacker et al., 2005) (14 and 12\%, respectively). In Rhinotermitidae, multiple studies failed to find evidence for colonies derived from three or more unrelated reproductives in the wild (Vargo, 2003; Vargo et al., 2003; DeHeer et al., 2005); however, low numbers of mixed family colonies have been reported in some R. flavipes populations (Bulmer et al., 2001 (14\%); Jenkins et al., 1999; DeHeer and Vargo, 2004 (3\%); Vargo and Carlson, 2006 (8\%); Vargo et al., 2006b (5.6\%)) and some populations of $R$. grassei are suggested to consist entirely of mixed family colonies (Clement et al., 2001; but see 
DeHeer et al., 2005). It is curious that the two basal termite species, Mastotermes and Zootermopsis, display a significant number of mixed family colonies. However, reports of these colony types in more derived termites are inconsistent and proportion of mixed family colonies is lower compared to the basal species. Part of this may be due to the limited number of studies involving basal termites compared to the more derived Rhinotermitidae and Termitidae. However, this may also suggest an evolutionary change in breeding structure where mixed family colonies become less frequent in the more derived lineages.

\section{Acknowledgements}

We thank MI Haverty and L Nelson for identifying and help in collecting Zootermopsis. Without their help, this study would not have been possible. We thank E Krafsur, E Vargo, C Husseneder and B Thorne for helpful comments and many discussions on termite evolution and population genetics. We also thank $\mathrm{C}$ Husseneder, E Vargo and C DeHeer for reviewing earlier versions of this manuscript and providing constructive criticism. The distribution map was prepared by the Geographic Information Systems Spatial Analysis Laboratory (GISSAL), Department of Geography, Kansas State University. This study was funded by a National Science Foundation grant (DEB9980253 to SK). This is journal article number 07-263-J of the Kansas Agricultural Experiment Station.

\section{References}

Aanen DK, Eggleton P (2005). Fungus-growing termites originated in African rain forest. Curr Biol 15: 851-855.

Aanen DK, Eggleton P, Rouland-Lefevre C, Guldberg-Froeslev T, Rosendahl S, Boomsma JJ (2002). The evolution of fungusgrowing termites and their mutualistic fungal symbionts. Proc Natl Acad Sci USA 99: 14887-14892.

Abe T, Bignell DE, Higashi M (eds) (2000). Termites: Evolution, Sociality, Symbioses, Ecology. Kluwer Academic Publishers Dordrecht, The Netherlands.

Aldrich BT (2005). Population genetics and colony structure of two Zootermopsis nevadensis subspecies. Ph.D. dissertation. Kansas State University.

Aldrich BT, Kambhampati S (2004). Microsatellite markers for two species of dampwood termites in the genus Zootermopsis (Isoptera: Termopsidae). Mol Ecol Notes 4: 719-721.

Atkinson L, Adams ES (1997). The origins and relatedness of multiple reproductives in colonies of the termite Nasutitermes corniger. Proc $R$ Soc Lond B 264: 1131-1136.

Broughton RE (1995). Mitochondrial DNA variation within and among species of termites in the genus Zootermopsis (Isoptera, Termopsidae). Ann Entomol Soc Am 88: 120-128.

Brunner PC, Fleminig C, Frey J (2002). A molecular identification key for economically important thrips species (Thysanoptera: Thripidae) using direct sequencing and a PCR-RFLP approach. Agric For Entomol 4: 127-136.

Bulmer MS, Adams ES, Traniello FJA (2001). Variation in colony structure in the subterranean termite Reticulitermes flavipes. Behav Ecol Sociobiol 49: 236-243.

Castle GB (1934). The damp-wood termites of western United States, genus Zootermopsis (formerly, Termopsis). In: Kofoid CA (ed). Termites and Termite Control, 2nd edn. University of California Press: Berkeley, CA. pp 273-310.

Clement JL, Bagneres AG, Uva P, Wilfert L, Quintana A, Reinhard J et al. (2001). Biosystematics of Reticulitermes termites in Europe, morphological, chemical and molecular data. Insect Soc 48: 202-215.

Crozier RH, Pamilo P (1996). Evolution of Social Insect Colonies: Sex Allocation and Kin Selection. Oxford University Press: Oxford, UK.

DeHeer CJ, Kutnik M, Vargo EL, Bagneres AG (2005). The breeding system and population structure of the termite Reticulitermes grassei in southwestern France. Heredity 95: 408-415.

DeHeer CJ, Vargo EL (2004). Colony genetic organization and colony fusion in the termite Reticulitermes flavipes as revealed by foraging patterns over time and space. Mol Ecol 13: $431-444$

Dieringer D, Schlotterer C (2003). Microsatellite analyzer (MSA): a platform-independent analysis tool for large microsatellite data sets. Mol Ecol Notes 3: 167-169.

Dronnet S, Chapuisat M, Vargo EL, Lohous C, Bagneres AG (2005). Genetic analysis of the breeding system of an invasive subterranean termite, Reticulitermes santonensis, in urban and natural habitats. Mol Ecol 14: 1311-1320.

Eggleton P (2000). Global patterns of termite diversity. In: Abe T, Bignell DE, Higashi M (eds). Termites: Evolution, Sociality, Symbioses, Ecology. Kluwer Academic Publishers: Dordrecht, The Netherlands. pp 25-51.

Goodisman MAD, Crozier RH (2002). Population and colony genetic structure of the primitive termite Mastotermes darwiniensis. Evolution 56: 70-83.

Hacker M, Kaib M, Bagine RKN, Epplen JT, Brandl R (2005). Unrelated queens coexist in colonies of the termite Macrotermes michaelseni. Mol Ecol 14: 1527-1532.

Harris WV, Sands WA (1965). The social organization of termite colonies. Symp Zool Soc London 14: 113-131.

Haverty MI, Page M, Nelson LJ, Blomquist GJ (1988). Cuticular hydrocarbons of dampwood termites, Zootermopsis: intraand intercolony variation and potential as taxonomic characters. J Chem Ecol 14: 1035-1058.

Haverty MI, Thorne BL (1989). Agonistic behavior correlated with hydrocarbon phenotypes in dampwood termites, Zootermopsis (Isoptera: Termopsidae). J Insect Behav 2: 523-543.

Hebert PDN, Cywinska A, Ball SL, de Waard JR (2003). Biological identifications through DNA barcodes. Proc $R$ Soc Lond B Biol Sci 270: 313-321.

Husseneder C, Brandl R, Epplen C, Epplen JT, Kaib M (1999). Within-colony relatedness in a termite species: genetic roads to eusociality? Behaviour 136: 1045-1063.

Husseneder C, Messenger MT, Su N, Grace JK, Vargo EL (2005). Colony social organization and population genetic structure of an introduced population of Formosan subterranean termite from New Orleans, Louisiana. J Econ Entomol 98: 1421-1434.

Husseneder C, Vargo EL, Grace JK (2002). Multilocus DNA fingerprinting and microsatellite genotyping: complementary molecular approaches to investigating colony and population genetic structure in subterranean termites. Sociobiology 40: 217-226.

Jenkins TM, Basten CJ, Kresovich S, Forschler BT (1999). Mitochondrial gene sequence questions Reticulitermes sp. social structure (Isoptera: Rhinotermitidae). Sociobiology 34: $161-172$.

Jones AG (2005). GERUD 2.0: a computer program for the reconstruction of parental genotypes from half-sib progeny arrays with known or unknown parents. Mol Ecol Notes 5: 708-711.

Jones SC, Lafage JP, Howard RW (1988). Isopteran sex ratios: phylgenetic trends. Sociobiology 14: 89-156.

Jones SC, Lafage JP, Wright VL (1981). Studies of dispersal, colony caste and sexual composition, and incipient colony development of Pterotermes occidentis (Walker) (Isoptera: Kalotermitidae). Sociobiology 6: 221-242.

Kambhampati S, Eggleton P (2000). Taxonomy and phylogeny of termites. In: Abe T, Bignell DE, Higashi M (eds). Termites: 
Evolution, Sociality, Symbioses, Ecology. Kluwer Academic Publishers: Dordrecht, The Netherlands. pp 1-23.

Krishna K, Weesner FM (eds) (1969). Biology of Termites, Vol. I-II. Academic Press: New York, NY.

Lewis PO, Zaykin D (2000). Genetic Data Analysis: Computer Program for the Analysis of Allelic Data. Version 1.0. Free program distributed by the authors over the internet from the GDA home page athttp://alleyn.eeb.uconn.edu/gda/.

Nei M (1973). Analysis of gene diversity in subdivided populations. Proc Natl Acad Sci USA 70: 3321-3323.

Noirot C, Bodot P (1964). L'essaimage d'Allognathotermes hypogeus Silv (Isoptera, Termitidae). Compt Rend 258: 3357-3359.

Pamilo P, Gertsch P, Thoren P, Seppa P (1997). Molecular population genetics of social insects. Annu Rev Ecol Syst 28: $1-25$.

Queller DC, Goodnight KF (1989). Estimating relatedness using genetic markers. Evolution 43: 258-275.

Reilly LM (1987). Measurements of inbreeding and average relatedness in a termite population. Am Nat 130: 339-349.

Ross KG (2001). Molecular ecology of social behavior: analyses of breeding systems and genetic structure. Mol Ecol 10: 265-284.

Schneider S, Roessli D, Excoffier L (2000). Arlequin: A Software for Population Genetic Analysis. Version 2.000. Genetics and Biometry Laboratory, University of Geneva: Switzerland.

Shellman-Reeve JS (2001). Genetic relatedness and partner preference in monogamous, wood-dwelling termite. Anim Behav 61: 869-876.

Stoeckle M (2003). DNA and the bar code of life. BioScience 53: 2-3.

Thompson GJ, Hebert PDN (1998). Population genetic structure of the neotropical termite Nasutitermes nigriceps (Isoptera: Termitidae). Heredity 80: 48-55.

Thorne BL (1997). Evolution of eusociality in termites. Annu Rev Ecol Syst 28: 27-54.

Thorne BL (1998). Biology of subterranean termites of the genus Reticulitermes. In: NPCA Research Report on Subterranean Termites Part I. National Pest Control Association: Dunn Loring, VA. pp 1-30.

Thorne BL, Breisch NL, Muscedere ML (2003). Evolution of eusociality and the soldier caste in termites: influence of intraspecific competition and accelerated inheritance. Proc Natl Acad Sci USA 100: 12808-12813.

Thorne BL, Haverty MI, Page M, Nutting WL (1993). Distribution and biogeography of the North American termite genus Zootermopsis (Isoptera: Termopsidae). Ann Entomol Soc Am 86: 532-544.

Thorne BL, Traniello JFA (2003). Comparative social biology of basal taxa of ants and termites. Annu Rev Entomol 48: 283-306.

Thorne BL, Traniello JFA, Adams ES, Bulmer M (1999). Reproductive dynamics and colony structure of subterranean termites of the genus Reticulitermes (Isoptera Rhinotermitidae): a review of the evidence from behavioral, ecological and genetic studies. Ethol Ecol Evol 11: 149-169.

Vargo EL (2003). Hierarchical analysis of colony and population genetic structure in the eastern subterranean termite, Reticulitermes flavipes, using two classes of molecular markers. Evolution 57: 2805-2818.

Vargo EL, Carlson JR (2006). Comparative study of breeding systems of sympatric subterranean termites (Reticulitermes flavipes and Rhageni) in central North Carolina using two classes of molecular genetic markers. Environ Entomol 35: 173-187.

Vargo EL, Husseneder C, Grace JK (2003). Colony and population genetic structure of the Formosan subterranean termite, Coptotermes formosanus, in Japan. Mol Ecol 12: 2599-2608.

Vargo EL, Husseneder C, Woodson D, Waldvogel MG, Grace JK (2006a). Genetic analysis of colony and population structure of three introduced populations of the Formosan subterranean termite (Isoptera: Rhinotermitidae) in the continental United States. Environ Entomol 35: 151-166.

Vargo EL, Juba TR, DeHeer C (2006b). Relative abundance and comparative breeding structure of subterranean termite colonies (Reticulitermes flavipes, Reticulitermes hageni, Reticulitermes virginicus, and Coptotermes formosanus) in a South Carolina Lowcountry site as revealed by molecular markers. Ann Entomol Soc Am 99: 1101-1109.

Weesner FM (1960). Evolution and biology of termites. Annu Rev Entomol 5: 153-170.

Wilson EO, Hölldobler B (2005). Eusociality: origin and consequences. Proc Natl Acad Sci USA 102: 13367-13371. 